\title{
Diversity Management: A Preliminary Review Of Selected Non-Profit North Carolina Independent Colleges \& Universities (NCICU)
}

M. Tony Bledsoe, (Email: bledsoem@meredith.edu), Meredith College

Rebecca J. Oatsvall, (Email: oatsvallr@meredith.edu), Meredith College

\begin{abstract}
While there may be wide-spread claims that diversity management exists in many organizations, there should be some means for verifying its existence. The purpose of this preliminary research is to review campus-wide documents and structure of schools in the NCICU to determine its transparency.
\end{abstract}

\section{INTRODUCTION}

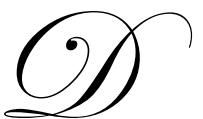

iversity is a reality for organizations today, presenting opportunities as well as challenges (Lakshminarayanan 2006). That diversity management exists is not in question. How it is manifested in the organization's structure is quite another issue. It is well-documented that diversity and diversity management have any number of definitions, interpretations, applications and implications. One of the challenges for this research effort was sorting through the myriad ways to define, interpret and discuss diversity management and how it is depicted in organizational structures. Another challenge was working through ambiguous language about diversity/diversity management in an attempt to identify a direction for research. The chosen path for this preliminary paper was to focus on structural processes within selected organizations.

Is diversity management, as some might say, becoming a cliché, reformed affirmative action, a defining matter or something else? In any event diversity management remains a question of what rather than if. This paper addresses a search to find and report how the organization-wide documents of selected private liberal arts colleges and universities reveal how diversity management that may be embedded and reflected within their structures.

\section{RESEARCH}

A review of literature reveals any number of definitions, interpretations and applications of diversity management (University of Vienna, 2007). "One of the most striking characteristics of the discourse of diversity is its tendency to evade definition" (Simmons-Welburn, 2000). Although these varying definitions may be seen in both business and academic settings, there appears to be a divergence between the models used by each. Both have social, economic, political, legal and educational threads. However, the academic model appears to have adapted a more structural approach. This model tends to reflect organizational values and beliefs which are consistent with desirable and identifiable diversity management outcomes. Also, the departure point may be seen along constituent lines since students, a major constituent of academic institutions, do not appear in the formal organizational chart which includes only employees. The academic model may more aptly be characterized as organizational structure. This invites an examination of certain published and distributed institutional documents such as mission statement, strategic goals, committees, staff positions, courses, workshops, catalogs and marketing materials. These attributes may demonstrate how the organization has positioned itself to address diversity management. Certainly, diversity management is too complex to be left to organization rhetoric. The diversity management process should be 
embedded in the very fabric of the organization and should emanate from the top and permeate the culture of the entire structure.

Because many business organizations have focused on conforming with current law, much of the literature about businesses focuses on the Human Resource Departments and how those segments of the organization can assure that legal requirements are met. In an effort to promote diversity, some academic institutions have followed the corporate model and given preferential treatment to minority candidates through admission of students and hiring of faculty and staff. One particular problem faced by academic institutions is that they must deal with three distinctly different constituencies: students, faculty, and staff. As a consequence, the goal for diversity may be addressed by differing methods in each of these three groups. It may no longer be acceptable to grant preferential treatment in admission of students, as is seen in the "new Michigan law (which) prohibits state and local governments from discrimination or granting preferential treatment based on race, sex, color, ethnicity, or national origin in public employment, public contracting, and public education" (Schmidt, 2007). In order to follow the law and the will of the voters, academic institutions may be forced to choose a course of action leading away from affirmative action. If affirmative action is wavering in the business arena, then it may already be diminishing in some academic situations (June, 2007).

In dealing with this change, both business and academic models are beginning to create a position entitled "Diversity Officer" (Gose, 2006). Further, many academic institutions have instituted both Diversity Officers and Diversity Committees comprised of members from the faculty, staff and student body. Additionally, this new direction regarding diversity is evidenced by course offerings, workshops, and constituent development including faculty, staff and students.

\section{DATA COLLECTION/METHODOLOGY}

The liberal arts institutions selected for this preliminary study are members of NCICU (North Carolina Independent Colleges and Universities). NCICU is described on the its website (http://www.ncicu.org) as:

NCICU is comprised of North Carolina's 36 private, non-profit liberal arts, comprehensive, and research colleges and universities accredited by the Southern Association of Colleges and Schools. NCICU represents independent higher education in the areas of state and federal public policy and on education issues with the other sectors of education in the state. We also provide research and information to and about private colleges and universities, conduct staff development opportunities and coordinate collaborative programs.

The colleges and universities surveyed for this project included all of the North Carolina private, non-profit liberal arts, comprehensive and research institutions that are members of the NCICU (North Carolina Independent Colleges and Universities). (http://www.ncicu.org/about_us.html.) See Appendix A for a list of institutions. This population was chosen because it is easily identifiable, accessible, diverse, and may be representative of a larger population which could be addressed in future research.

The first step in data collection was to search each educational institution's website to determine if the homepage and available documents referenced diversity. Specific information on the institutional definition of diversity was sought along with evidence that the organizational structure supported diversity. It is anticipated that in subsequent research this information will supplement data collected directly from the institutions.

The second step was to survey each institution to obtain diversity information. Based upon information received from the Dean of Enrollment Planning and Institutional Effectiveness at Meredith College, it was learned that the individual at each member institution who was charged with institutional effectiveness would be the best source of diversity information within the institution. When it was not possible to identify such a person, the questionnaire was sent to the institution's Registrar. The e-mail address and name of each person were obtained from the NCICU website (http://www.ncicu.org). The survey was conducted on-line in order to simplify and expedite the response process for the institutional representative and also to provide anonymity for the respondents. 
Respondents were informed that if they wished survey results, they could e-mail the researchers for that information. The original survey was sent 10/11/2006 with a follow-up reminder survey sent 10/26/2006.

A major focus of the survey was to obtain information about whether diversity was referenced in the institution's Mission Statement, published goals, academic catalogs and recruiting materials. Additional information was gathered about committee structure, curriculum, diversity training and diversity policies. Each institution was asked to provide its definition of diversity and to identify whether diversity was supported by its organizational structure.

\section{FINDINGS}

Responses were received from 13 of the $36 \mathrm{NCICU}$ institutions surveyed for a return rate of $36 \%$. The reporting format for the findings/implications follows the order of the survey questionnaire. The purpose is to clearly state the information provided by the respondents. (Survey results are found in Appendix B.)

The college/university response to a question asking if diversity is referenced on their homepage shows only $30.8 \%$ yes/ $69.2 \%$ no. While at first glance this appears to be low, there may valid reasons for not including this. This may not imply an overt omission and may not be an accurate assessment of the institution's diversity management intent. It might be the institution has other ways of reflecting its diversity commitment.

Response to a question about the inclusion of diversity management in the institutional mission statements shows $84.6 \%$ yes $15.4 \%$ no. The positive response shows that these institutions have a strong belief in diversity and it may be an integral part of the strategic level decision making.

Responses to the question about published intuition-wide goals were $76.9 \%$ yes $/ 23.1 \%$ no. The interesting part of this is that when asked if diversity was a major goal the response shows $54.5 \%$ yes $/ 45.5 \%$ no. Institutionwide goals may be interpreted as an indicator of values held by the organization. These values are guidelines within which the organizational culture develops.

The undergraduate catalog is a vital document in any college/university. Responses reveal that $61.5 \%$ include diversity and $38.5 \%$ do not have it in their undergraduate catalogs. The implications may vary since such information may be demonstrated in other college documents. It does raise the question of why reference is not made in this important document.

Recruiting is a vital part of colleges/universities as they attempt to gain a competitive advantage. The responses to this survey question show that $69.2 \%$ include diversity in its recruitment material while $30.8 \%$ do not. Does this indicate a lack of sensitivity to diversity management? Perhaps it does, or not. It may be a matter of examining a composite of all organizational material documents to more completely understand the organization's strategy.

Organizational structure offers a picture of how organizations position personnel to achieve stated goals. Results of the question about diversity committees, councils and groups produced a $23.1 \%$ yes/76.9\% no response. This, considered in conjunction with responses about institution-wide goals leads the researchers to infer that these organizational structures do not appear to support its stated goals and values.

The undergraduate curriculum provides an insight into the academic institution's educational efforts to communicate its values. When asked about the presence of a diversity course, there was a $23.1 \%$ yes/ $76.9 \%$ no response. Of the yes responses $25 \%$ indicated that it is required of all students and in $75 \%$ of these institutions it is not. It is interesting how these rates correspond to the question about structural factors such as diversity committees, councils and groups. Again, there appears to be a lack of positive correlation with the responses about institutionwide goals. 
Training may be taken as an indicator of what an organization views as an important function. Diversity training for students reveals response rates of $38.5 \%$ yes $161.5 \%$ no while figures for faculty training shows $23.1 \%$ yes/76.9\% no and the numbers for staff training are $30.8 \%$ yes/ $69.2 \%$ no. It is notable that rates for the three groups are at or above rates shown for diversity curriculum efforts, but below the percentage of institutions claiming diversity as a major goal.

Mission statements identify purpose, goals set the direction for performing the mission and policy influences member actions and behaviors. The respondent rate to the question of having a diversity policy in the student handbook was $38.5 \%$ yes/ $61.5 \%$ no. For faculty/staff handbooks the rate was $23.1 \%$ yes/ $76.9 \%$ no. It appears that educational institutions place more emphasis on student training than on faculty/staff training.

The designation of a specific individual in an organization who is responsible for diversity management may signal the importance of diversity to the organization. Reaction to the question of having a position such as Directory of Diversity programs for students brought responses of $15.4 \%$ yes/ $84.6 \%$ no. The responses when the question was applied to faculty/staff were even lower at $7.7 \%$ yes/ $92.3 \%$ no. Alone these numbers may not be too revealing; however taken in context of the entire organizational structure they may be yet another indicator of importance and value (or lack thereof) of the concept and practice of diversity management.

\section{IMPLICATIONS AND IMPLEMENTATION STRATEGIES}

Most of the organizations surveyed included diversity in organizational goals but failed to include appropriate references in their published documents. The suggested remedy is inclusion of appropriate documentation in key publications. Such inclusion would make visible the institution's commitment to diversity. Clear statements in the mission, homepage, published institution goals and recruiting materials would send a strong and consistent message that the institution values diversity.

From an organizational structure standpoint, the challenge is to reflect the organization's commitment to its stated goals through its committees, councils and institutional hierarchy. Through inclusion of appropriate committees or councils in the formal organizational structure, institutions can assure participation by all appropriate constituents in the pursuit of meeting the diversity goals. The level of the responsible administrator signals the importance of this goal to the institution and to its constituents; therefore a strategic level administrator should be appointed to spearhead this effort. Further confirmation of the importance of this initiative would be evidenced by participation of members of the Board of Trustees.

Organizations tend to spend discretionary funds on initiatives that they value. If diversity is one of these, organizations should be prepared to fund appropriate training. Administrators, faculty, staff and students should be included in training and development activities that enhance and encourage the organization's commitment to diversity.

\section{SUMMARY}

Findings of this preliminary diversity management study indicate how organizational rhetoric about goals and policies differs from what is reported in the questions of structure. It would seem that the first of these questions which address the institutions' missions, goals and values would be supported by the second set of questions that address organizational structure. Examination of the survey responses reveals some notable differences. For example question one, about homepage, has a negative response rate to diversity management being included while questions of mission, goals, catalog and recruiting have positive ones. Questions one through five primarily address what the organization is telling its constituents, while questions six through ten address specific manifestations of these messages in terms of structural support to facilitate policies. Questions six through ten also represent more of a personnel focus reflecting the traditional corporate model where diversity management was relegated to the Human Resource Department. 
Recent literature led the researchers to expect a marked difference in the organizational structures of academic organizations and corporate organizations. Washington State University is a leader in the academic community for its appointing a Chief Diversity Officer. "Harvard University, Texas A\&M University, and the Universities of California at Berkeley, Texas at Austin, and Virginia, among others, have created chief-diversityofficer positions in the past two years" (Gose, 2006). Our research revealed only one institution that had created such a position. This may be explained by the composition of the reporting group, which is made up of small, independent, liberal arts colleges/universities in North Carolina where the information may not be readily available in existing publications. Further research may reveal a stronger emphasis on diversity management which is documented in the organizational structure and by the creation of an office or officer for diversity management. Additionally, evidence of the value of diversity management to the academic community may be demonstrated by an emphasis on training for students, staff and faculty.

Simply stated, the purpose of this study was to discover what approaches some private liberal arts colleges/universities were taking to address the issue of diversity management. Most organizations have both rhetoric and structure to support stated beliefs and values. Additionally, it would seem the two should be mutually supportive, but this was not supported by institutional responses.

Two settings, corporate and academic, appear to have different approaches to implementing diversity management. The corporate model leans more toward legal considerations guided by human resource professionals, while the academic must be responsive to three distinct constituent groups, faculty, staff and students. Academic institutions must have policies unique to each group while many corporate organizations may have only one set of policies applicable to all employees.

\section{EMERGING ISSUES FOR FURTHER STUDY}

- $\quad$ Examination of diversity management models (business vs. academic)

- $\quad$ Study of structure vs. culture

- $\quad$ Clarification of definitions and applications of diversity management

- $\quad$ Examination of governance boards (comparative study of business and academic)

- $\quad$ Review of centralization/decentralization of diversity management within the organization

- Examination of connections: beliefs to values, values to actions, actions leading to outcomes/manifestations

- $\quad$ Assessment of constituent attitudes toward diversity management

- Analysis of bottom-line impact of diversity management (positive or negative) 
APPENDIX A

\section{List Of Colleges \& Universities Surveyed}

\begin{tabular}{|c|c|}
\hline Name of College or University & Website \\
\hline Barton College & www.barton.edu \\
\hline Belmont Abbey College & www.belmontabbeycollege.edu \\
\hline Bennett College for Women & www.bennett.edu \\
\hline Brevard College & www.brevard.edu \\
\hline Cabarrus College of Health Sciences & www.cabarruscollege.edu \\
\hline Campbell University & www.campbell.edu \\
\hline Catawba College & www.catawba.edu \\
\hline Chowan University & www.chowan.edu \\
\hline Davidson College & www.davidson.edu \\
\hline Duke University & www.duke.edu \\
\hline Elon University & www.elon.edu \\
\hline Gardner-Webb University & www.gardner-webb.edu \\
\hline Greensboro College & www.gborocollege.edu \\
\hline Guilford College & www.guilford.edu \\
\hline High Point University & www.highpoint.edu \\
\hline Johnson C. Smith University & www.jcsu.edu \\
\hline Lees-McRae University & www.lmc.edu \\
\hline Lenoir-Rhyne College & www.lrc.edu \\
\hline Livingstone College & www.livingstone.edu \\
\hline Louisburg College & www.louisburg.edu \\
\hline Mars Hill College & www.mhc.edu \\
\hline Meredith College & www.meredith.edu \\
\hline Methodist University & www.methodist.edu \\
\hline Montreat College & www.montreat.edu \\
\hline Mount Olive College & www.moc.edu \\
\hline N.C. Wesleyan College & www.ncwc.edu \\
\hline Peace College & www.peace.edu \\
\hline Pfeiffer University & www.pfeiffer.edu \\
\hline Queens University of Charlotte & www.queens.edu \\
\hline St. Andrews Presbyterian College & www.sapc.edu \\
\hline St. Augustine's College & www.st-aug.edu \\
\hline Salem College & www.salem.edu \\
\hline Shaw University & www.shawuniversity.edu \\
\hline Wake Forest University & www.wfu.edu \\
\hline Warren Wilson College & www.warren-wilson.edu \\
\hline Wingate University & www.wingate.edu \\
\hline
\end{tabular}




\section{APPENDIX B}

\section{Survey Results}

\begin{tabular}{|c|c|c|c|}
\hline \multicolumn{2}{|r|}{ Survey Question } & $\%$ Yes & $\% \mathrm{No}$ \\
\hline 1. & Does your Homepage make reference to diversity? & $30.8 \%$ & $69.2 \%$ \\
\hline 2. & Does your Mission Statement include or imply the inclusion of diversity? & $84.6 \%$ & $15.4 \%$ \\
\hline 3a. & Do you have published institution-wide goals? & $76.9 \%$ & $23.1 \%$ \\
\hline 3b. & If $3 a$ is "yes," is diversity a major goal? & $54.5 \%$ & $45.5 \%$ \\
\hline 4. & Does your Undergraduate Academic Catalog include a statement about diversity? & $61.5 \%$ & $38.5 \%$ \\
\hline 5. & Do your undergraduate recruiting materials include diversity information? & $69.2 \%$ & $30.8 \%$ \\
\hline 6. & Do you have a Diversity Committee, Council or other formal diversity group? & $23.1 \%$ & $76.9 \%$ \\
\hline $7 \mathrm{a}$. & Does your undergraduate curriculum include a specific diversity course? & $23.1 \%$ & $76.9 \%$ \\
\hline $7 \mathrm{~b}$. & If 7a is "yes," is the course required of all students? & $25.0 \%$ & $75.0 \%$ \\
\hline $8 \mathrm{a}$. & Do you have diversity training for students? & $38.5 \%$ & $61.5 \%$ \\
\hline $8 \mathrm{~b}$. & Do you have diversity training for faculty? & $23.1 \%$ & $76.9 \%$ \\
\hline $8 \mathrm{c}$. & Do you have diversity training for staff? & $30.8 \%$ & $69.2 \%$ \\
\hline 9a. & Do you have a diversity policy in your student handbook? & $38.5 \%$ & $61.5 \%$ \\
\hline $9 \mathrm{~b}$. & Do you have a diversity policy in your faculty/staff handbooks? & $23.1 \%$ & $76.9 \%$ \\
\hline 10a. & Do you have a designated Director of Diversity programs for students? & $15.4 \%$ & $84.6 \%$ \\
\hline $10 \mathrm{~b}$. & Do you have a designated Director of Diversity programs for faculty/staff? & $7.7 \%$ & $92.3 \%$ \\
\hline
\end{tabular}

\section{REFERENCES}

1. Basset-Jones, Nigel (2005). The Paradox of Diversity Management, Creativity and Innovation. Creativity \& Innovation Management. Vol. 14, Issue 2, pp 169-175.

2. Brown, Roger (2004). The future structure of the sector: What price diversity? Perspectives. Vol. 8, Number 4, pp 93-99.

3. Brown, William A. (2002). Inclusive Governance Practices in Nonprofit Organizations and Implications for Practice. Nonprofit Management \& Leadership. Vol. 12, Issue 4, pp 369-386.

4. Carrell, Michael R., Mann, Everett E., Sigler, Tracey Honeycutt (2006). Defining Workforce Diversity Programs and Practices in Organizations: A Longitudinal Study. Labor Law Journal. Vol. 57, Issue 1, pp 5-12.

5. Gilbert, Juan E. (2006). Applications Quest: Computing Diversity. Communications of the ACM. Vol. 49 Issue 3, pp 99-104.

6. Gose, Ben (2006). The Rise of the Chief Diversity Officer. The Chronicle of Higher Education. September 29, 2006, pp. B1-B5.

7. June, Audrey Williams (2007). Federal Appeals Court Overturns Extension for Michigan Universities on Complying with Preferential Treatment. The Chronicle of Higher Education, Today's News. January 2, 2007. Obtained on 1/2/2007 at http://chronicle.com/daily/2007/01/2007010203n.htm.

8. Lakshminarayanan, Sambhavi (2006). A Social Marketing Based Strategy For Planning Diversity Events. Journal of Diversity Management. Vol. 1, Number 1, pp 39-47.

9. Lawler, Andrew (2005). Harvard Pledges \$50 Million To Boost Diversity on Campus. Science. 5/20/2005, Vol. 308 Issue 5725, p 1102.

10. North Carolina Independent Colleges and Universities website (2007). http://www.ncicu.org.

11. Patterson, Glenys (2001). The Applicability of Institutional Goals to the University Organisation. Journal of Higher Education Policy and Management. Vol. 23, No 2, 2001, pp 159-169.

12. Schauber, Ann C. (2001). Effecting Extension Organizational Change Toward Cultural Diversity: A Conceptual Framework. Journal of Extension. Vol. 39, No 3, June 2001. Obtained on 12/14/2006 at http://www.joe.org/joe/2001 june/a1.html.

13. Schmiddt, Peter (2007). Legal Battles Over a Ban on Preferences Heat Up. The Chronicle of Higher Education. January 5, 2007. pp A1, A24. 
14. Shackelford, William G. (2006). The Changing Definition Of Workplace Diversity. The Black Collegian Online. Obtained on 12/6/2006 at http://www.black-collegian.com/issues/2ndsem03/changing20032nd.shtml.

15. Sherman, Natalie I. (2006). Diversity Office Takes First Steps. The Harvard Crimson. Published on 6/7/2006. Obtained on 12/16/2006 at http://www.thecrimson.com/printerfriendly.aspx?ref=513818.

16. Simmons-Welburn, Janice. (2000). Rating Library \& Institutional Priorities in Managing Diversity: Results of a Preliminary Study. Obtained on 9/8/2006 at http://www.arl.org/diversity/leading/issue13/simwel.html.

17. Singh, Val (2002) Managing Diversity for Strategic Advantage. Cranfield Management Research Institute - Cranfield School of Management. Obtained on 2/2/2007 at http://www.som.cranfield.ac.uk/som/research/centres/cdwbl/projects2003/22.asp.

18. Singh, Val and Point, Sebastien (2003). On-Line Corporate Diversity statements: A Study of Top Companies in Eight European Countries. Cranfield Management Research Institute - Cranfield School of Management. Obtained on 2/2/2007 at http://www.som.cranfield.ac.uk/som/research/centres/cdwbl/projects2003/25.asp.

19. Singh, Val, Schiuma, Gianni, and Vinnicombe, Susan (2002). The Assessment of Diversity Management Performance across 11 Private and Public Sector Organisations. Cranfield Management Research Institute - Cranfield School of Management. Obtained on 2/2/2007 at http://www.som.cranfield.ac.uk/som/research/centres/cdwbl/projects2003/23.asp.

20. Symonds, William C. ( 2006). Campus Revolutionary. Business Week, 2/27/2006 Issue 3973, pp 64-70.

21. University of Vienna website (2007). Diversity Management. Obtained on 1/1/2007 at http://www.univie.ac.at/diversity/php/management.html.

22. Varley, Pamela (2006). Values in Conflict: The Furor over Admissions Policy at a Popular Virginia Magnet School. Case Studies in Public Policy \& Management, Harvard University, 8/31/2006. Obtained on 2/1/2007 at http://www.ksgcase.harvard.edu/casetitle.asp?caseNo=1848.0. 